\title{
Contribuições do lean office no departamento financeiro de uma empresa que utiliza um Centro de Serviço Compartilhado
}

\section{Shared Service Center: Lean office in finance department}

Article Info:

Article history: Received 2021-05-20 / Accepted 2021-07-07 / Available online 2021-07-07

doi: $10.18540 /$ jeecvl7iss3pp12832-01-14e

Lucas Benini

ORCID: https://orcid.org/0000-0002-5850-1399

Departamento de Engenharia Mecânica, TEM - Universidade Federal Fluminense, UFF, Brasil

E-mail: lucasbenini@id.uff.br

Rafaela Souza Silva

ORCID: https://orcid.org/0000-0001-7302-2129

Departamento de Engenharia de Produção e Mecânica, DEP - Universidade Federal de Viçosa,

UFV, Brasil

E-mail: rafaela.souza@weme.nu

\section{Resumo}

O lean office tem como objetivo reduzir os desperdícios nas áreas de apoio de uma empresa. Um setor que pode se beneficiar das ferramentas abordadas pelo lean office é o setor financeiro. Neste setor são efetuadas diversas atividades que, constatadas como desperdícios, não agregam valor ao cliente e comprometem a sinergia das atividades operacionais da empresa. O objetivo deste trabalho é aplicar ferramentas do lean office nas atividades do departamento financeiro de uma empresa com Centro de Serviços Compartilhados (CSC). Apesar dos vários trabalhos reportados na literatura de lean, não foram encontrados trabalhos que abordam o tema lean office no setor financeiro de empresa, considerando o impacto do cenário causado pela COVID-19. Foram elaborados os mapas do fluxo de valor do estado atual e do estado futuro do processo de solicitação de compras. Com a implementação das ferramentas, considerando os resultados preliminares e a sugestões para eliminação dos desperdícios identificados, o lead time de solicitação de compras diminuiu $26 \%$ em relação ao período pré-COVID-19 e 22\% considerando-se o período pós-COVID-19.

Palavras-chave: Lean office. Solicitação de compras. Desperdícios.

\section{Abstract}

The lean office aims to reduce waste in the support areas of a company. One sector that can benefit from the tools covered by the lean office is the financial sector. In this sector, various activities are carried out which, as waste, do not add value to the customer and compromise the synergy of the company's operational activities. The objective of this work is to apply lean office tools in the activities of the financial department of a company with a Shared Services Center (CSC). Despite the various works reported in the lean literature, no studies were found that address the lean office theme in the company's financial sector, considering the impact of the scenario caused by COVID19. Maps of the value flow of the current state and the future state of the purchase request. With the implementation of the tools, considering the preliminary results and suggestions for the elimination of the identified wastes, the request lead time of $26 \%$ in relation to the pre-COVID-19 period and $22 \%$ considering the post-COVID-19 period.

Keywords: Lean office. Purchase request. Waste. 


\section{Introdução}

As organizações tem procurado melhorar cada vez mais os seus processos e a diminuírem seus desperdícios para manter sua vantagem competitiva. Uma maneira de obter essa melhora é através do lean thinking, ou pensamento enxuto. O lean thinking é uma maneira de melhorar e (re)organizar um ambiente produtivo. Ao entender o que é valor para o cliente é possível identificar e eliminar desperdícios, principalmente no que tange a velocidade no atendimento ao cliente, a flexibilidade para se ajustar aos desejos específicos e a qualidade do produto ou serviço ofertado (Costa e Jardim, 2010).

O lean thinking surgiu no período Pós Segunda Guerra Mundial, na década de 50, quando o executivo da Toyota, Taiichi Ohno, criou um sistema de produção que visava identificar e eliminar os desperdícios. Na década de 90, surgiu o conceito lean manufacturing, ou produção enxuta, no livro "A máquina que mudou o mundo" de autoria de Womack et al. (1992). O termo "enxuta" refere-se à redução ou eliminação de desperdícios e de atividades que não agregam valor ao produto ao longo do processo produtivo.

O lean manufacturing visa agregar valor aos produtos, com o menor custo possível, de forma a alcançar a satisfação dos clientes (Tice et al., 2005; Cardoso e Alves 2013; Gentil e Terra, 2015; Benini e Rocha, 2019). Os desperdícios abordados pelo lean manufacturing são: espera, estoque, super processamento, superprodução, transporte, movimentos desnecessários e defeitos (Womack e Jones, 1990).

Bulhões (2009) destaca que, devido ao impacto do trabalho de Womack et al. (1992), na década de 90 passou-se a defender a ideia de que o lean manufacturing poderia ser aplicado a qualquer tipo de atividade e em outros setores. Womack e Jones (1996), no livro "Mentalidade Enxuta", propuseram uma abordagem orientada para implementação do lean manufacturing em empresas. Com isso, o termo deixou de se restringir à Toyota e à produção e passou a ser utilizado nas mais diversas áreas empresariais e nos diversos setores do mercado, como a área administrativa (lean office), de serviços (lean service), a ambiental (lean environment), a logística (lean logistics), entre outras (Benini e Rocha, 2019).

Em relação a área administrativa, o lean office corresponde a um sistema de gestão voltado para os processos em que o fluxo está vinculado a informações e conhecimentos, os quais podem gerar custos e sobrecarregar os processos de manufatura (Mcmannus, 2005; Tammela, 2017). O lean office visa manter objetivos ligados à redução de custos, a eliminação de retrabalho, a minimização de problemas de comunicação, a redução e eliminação de atividades que não agregam valor aos processos, ao aumento de produtividade, a eficiência das funções administrativas e a melhor utilização da área de trabalho nos ambientes administrativos (Tapping e Shuker, 2010; Evangelista et al. 2013).

Vários trabalhos demonstram a aplicabilidade do lean office em diferentes setores: Herzog (2003) descreveu em seu artigo a utilização do lean office no setor de recursos humanos da empresa Alcoa e na cotação de pedidos da empresa Bosh; Turati (2007) apresentou a lean office executado no Ministério da Fazenda; Santos (2010) abordou os conceitos lean na contabilidade em empresas que já possuíam o pensamento enxuto; Scheibler et al. (2010) aplicaram os princípios lean office em um banco cooperativo; Seraphim et al. (2010) utilizaram os conceitos do lean office no nível institucional na área da prestação de serviços, particularmente no segmento de saúde; Cardoso et al. (2012) apresentaram a aplicação do lean office no processo de auditoria de certificação de sistema de Gestão da Qualidade Aeroespacial; Chen e Cox (2012) adotaram o lean office no setor de projetos de uma empresa de produtos eletrônicos; Cardoso e Alves (2013) efetuaram uma análise crítica da implementação do lean office em 3 estudo de casos: no atendimento fiscal de um setor administrativo público, no atraso de encaminhamentos de informações técnicas de uma distribuidora de combustíveis, e na implementação de bolsas de estudo em um programa de pós-graduação; Evangelista et al. (2013) estudaram a aplicabilidade dos conceitos do lean office em uma empresa de transportes; França (2013) empregou o lean office em uma empresa de contabilidade; Gentil e Terra (2015) apresentaram as vantagens competitivas do lean office em estudos de casos em 
empresas de diferentes ramos de atividades; Monteiro et al. (2015) usaram o lean office em uma organização do setor público; Calsavara (2016) dissertou sobre o lean office na concepção de unidades bancárias; Ferreira (2016) adotou ferramentas lean na área administrativa e gerencial de um banco; Ishizaka et al. (2016) executaram o lean office no departamento de marketing de uma instituição financeira; Freitas et al. (2018) em sua revisão bibliográfica apontaram os benefícios do lean office em estudos de casos da construção civil, indústria, administração púbica, educação, e setor de serviços; Monteiro et al. (2017) detalharam o uso de ferramentas do lean office no departamento de logística de uma empresa; Freitag et al. (2018) pesquisaram sobre o lean office no contexto da transformação digital em um estudo de caso de uma empresa de IoT (Internet of Things); Sukma et al. (2018) empregaram o lean office no Serviço de Registro Civil em um órgão governamental; Magalhães et al. (2019) trataram do uso do lean office na secretaria de um programa de pós-graduação de uma instituição de ensino superior.

Deve-se destacar que, apesar dos benefícios do lean office, a aplicação do lean thinking em ambientes administrativos é mais difícil do que na manufatura, uma vez que os desperdícios na geração de informações e execução de serviços são mais difíceis de identificar e os cenários de trabalhos são muitas vezes difíceis de visualizar (Mcmannus, 2005; Gentil e Terra, 2015). Isto por que as atividades administrativas geram informações da consecução de determinadas tarefas. Na área administrativa os colaboradores são constantemente interrompidos, estão muito atarefados, seguem procedimentos extremamente burocráticos, muitas vezes desconhecem processos internos, utilizam documentos supérfluos que exigem assinaturas desnecessárias, etc. (Tammela, 2017).

A identificação dos desperdícios na geração de informações é ainda mais complexa no caso de empresas que utilizam de Centros de Serviços Compartilhados (CSC). De forma geral, num CSC a organização empresarial é estruturada de forma que uma central administrativa absorve as atividades de back office (como processamento de pedidos, pedido de compras, fluxo de caixa, contas a pagar e receber, atividades contábeis e fiscais, etc.) de cada unidade de negócio, ou departamento funcional ou filial. Deste modo, o CSC efetua as atividades administrativas e as filiais, plantas e subsidiárias podem focar atividades front office (vendas, produção e distribuição) (Scheibler et al., 2010).

A empresa analisada neste trabalho utiliza um CSC, com plantas em diferentes estados. O departamento financeiro da empresa apresenta demora no processamento de pedidos de compras e pedidos de reembolso, pois processa estes pedidos oriundos de 3 filiais. A demora no atendimento destes pedidos foi agravada em virtude da pandemia originada pelo vírus COVID-19. Em março de 2020 a Organização Mundial de Saúde (OMS) decretou estado de pandemia em virtude do novo Coronavírus (COVID-19). Essa situação obrigou as empresas a tomarem medidas de prevenção e de enfrentamento à epidemia, como trabalho remoto, diminuição da jornada de trabalho, antecipação de férias, encerramento de contratos, etc.

O objetivo principal deste trabalho é aplicar ferramentas do lean office nas atividades do departamento financeiro de uma empresa com Centro de Serviços Compartilhados (CSC), visando a redução do tempo de atendimento e aumento da qualidade das atividades. Os objetivos específicos são: mapear do fluxo de valor das solicitações de compra; identificar e eliminar os desperdícios do processo de compras e propor melhorias.

\section{Procedimentos metodológicos}

A metodologia de pesquisa utilizada neste trabalho é a Pesquisa-Ação. De acordo com Gil (2002) a pesquisa ação possui base empírica que é concebida e realizada associando-se uma ação ou a resolução de um problema coletivo, sendo que os pesquisadores e participantes representativos do problema estão envolvidos de modo cooperativo ou participativo. De acordo com Turrioni e Mello (2009), a condução de uma pesquisa ação segue cinco fases: planejar, coletar dados, analisar dados e planejar ações, implementar ações, avaliar resultados e gerar relatório. Para Coughlan e 
Couglan (2002) a pesquisa ação exige encarar situações de realidade organizacional de constante mudança em tempo real, requerendo habilidades especiais para diagnose e intervenção.

Visando identificar os desperdícios do lean office no setor financeiro da empresa em questão, foram selecionados os processos deste setor com maior lead lime: o processo de solicitação de compras e o processo de solicitação de reembolso. Neste trabalho é abordado somente o processo de solicitação de compras. Destaca-se que a pandemia causada de pelo COVID-19 impactou nas etapas deste processo, uma vez que foram incorporadas novas etapas que, consequentemente, modificou o lead time deste processo. Com o intuito de diminuir o lead time, seguindo-se as recomendações de Tapping e Sucker (2003) e de Tapping et al. (2010), foram executados os seguintes procedimentos: elaboração o mapa do estado atual do processos de solicitação de compras para os períodos pré e pós-COVID-19 (a elaboração destes mapas seguiu as recomendações e metodologia de Rother e Shook (2003)); diagnóstico dos desperdícios; propostas de melhorias; implementação parcial destas propostas e elaboração do mapa do estado futuro. Deve-se destacar que a empresa abordada neste trabalho possui atualmente 70 colaboradores, com filiais nos estados de São Paulo e de Santa Catarina.

Em 11 de março de 2020 a OMS decretou pandemia decorrente do COVID-19. Os dados coletados antes desta data são denominados pré-COVID-19 e os dados coletados após esta data são denominados como pós-COVID-19. O período de coleta dos tempos para elaboração dos mapas de fluxo de valor no período pré-COVID-19 foi de janeiro e fevereiro de 2020, e o período pós-COVID19 foi de março até junho de 2020. A coleta de dados foi baseada no banco de dados do sistema ERP (enterprise resource planning), considerando 1.189 solicitações compras pré-COVID e 944 solicitações de compra no período pós-COVID-19.

\section{Resultados}

\subsection{Identificação e mapeamento do processo de solicitação de compras}

O processo de solicitação de compras pré-COVID-19 é composto de 7 etapas: analisar as demandas do time requerente; efetuar o orçamento; solicitar as compras; aprovação da compra, pelo líder; faturar a solicitação; analisar o faturamento e por fim efetuar o pagamento. Com a pandemia causada pelo COVID-19 o processo de solicitação de compras passou a ter 10 etapas: analisar as demandas, efetuar três orçamentos, solicitar a compra, líder aprová-la, contactar o fornecedor, receber a nota fiscal e o boleto relativo à compra, faturar a solicitação de compras, analisar o pedido, agendar o pagamento e, por fim, efetuar o pagamento.

A Figura 1 apresenta o mapa do estado atual do processo de solicitação de compra préCOVID-19. Conforme se observa nesta figura o lead time deste processo é de 16.487 min (34,3 dias úteis com jornada de $8 \mathrm{~h}$ de trabalho), sendo que o tempo de valor agregado na atividade é de 625 min (1,3 dias). Na linha de tempo do mapa do estado atual se observa que de há duas esperas entre a aprovação do líder e o faturamento da solicitação de 4.800 min e entre a análise do financeiro e o pagamento de $4.800 \mathrm{~min}$. Destaca-se que estes tempos podem variar por causa da política de prazo de pagamento da empresa, que é de 30 dias, iniciando da etapa denominada 'faturar a solicitação'. Além disso, os pagamentos são efetuados por ordem bancária na sexta-feira que antecede a semana de pagamento, podendo afetar estes tempos de espera. Do ponto de vista do usuário, há um desperdício, contudo, do ponto de vista do setor financeiro, esta espera permite efetuar uma melhor previsão do caixa.

A Figura 2 apresenta o mapa do estado atual de solicitação de compra pós-COVID-19. Em relação ao processo de solicitação de compras, observa-se que pós-COVID-19 há mais etapas inseridas no processo (passou de 7 para 10 etapas), impactando no lead time do processo de compras. As atividades que agregam valor ao cliente possuem duração $245 \mathrm{~min}(0,5$ dias úteis com $8 \mathrm{~h}$ de jornada de trabalho) e o lead time é de 6.485 min (13,5 dias). Na linha de tempo do mapa do estado atual deste processo observa-se que os desperdícios de espera estão entre as etapas de aprovação da compra pelo líder e contactar o fornecedor, com um tempo de $2.400 \mathrm{~min}$. 
Deve-se destacar que o processo de solicitação de compra teve uma redução em seu lead time em torno de 5,5\% em relação ao período pré e pós-COVID-19. Esta redução pode ser explicada em virtude da análise diária dos pedidos no sistema ERP no período pós-COVID-19. Além disso, o prazo de pagamento da solicitação de compras pré-COVID-19 era calculado com base nos 30 dias após a emissão de nota fiscal, e no período pós-COVID-19 é calculado com base nos 30 dias após o faturamento do pedido no sistema ERP.

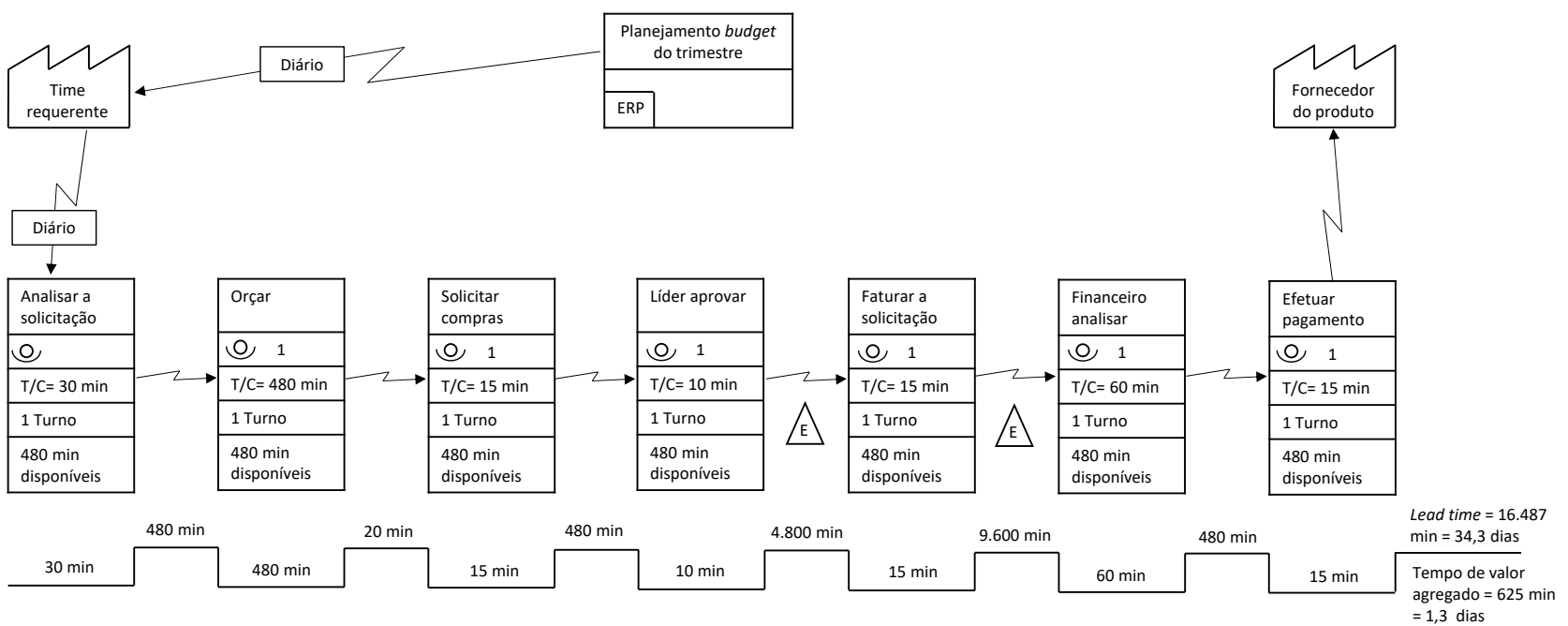

Figura 1 - Mapa do estado atual do processo de solicitação de compras pré-COVID-19.

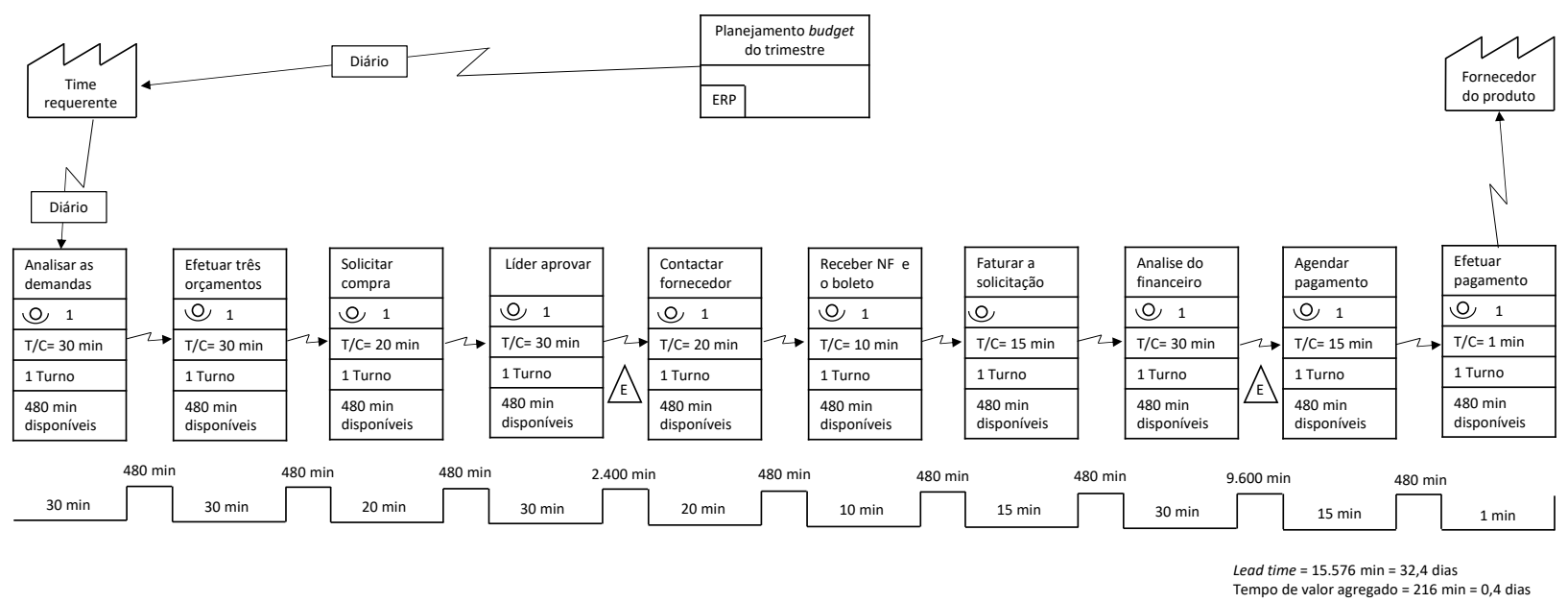

Figura 2 - Mapa do estado atual do processo de solicitação de compras pós-COVID-19.

\subsection{Desperdícios identificados no processo de solicitação de compras}

Considerando os desperdícios abordados pelo lean office, os desperdícios que foram identificados no processo de solicitação de compras foram os mesmos nos cenários pré-COVID-19 e pós-COVID-19, diferenciando-se na intensidade em que apareceram:

- Superprodução: este desperdício era claramente percebido no pré-COVID-19, pois os colaboradores efetuavam solicitações de compra com informações erradas. Isto gerava solicitações de compra paradas no sistema ERP (enterprise resource planning), consumindo parte do orçamento do time, sendo que estas solicitações de comprar, com informações erradas, eram finalizadas. Este desperdício ocorria mesmo com a utilização de um manual de utilização do sistema ERP, que foi produzido no momento de implementação do sistema Sankhya ${ }^{\circledR}$. Em virtude de linguagem confusa e de difícil entendimento, este manual acabava não sendo utilizado pelos solicitantes.

- Superprocessamento: este desperdício ocorre pela duplicidade de informações que o colaborador inseria no sistema ERP. A sua implementação foi pouco estruturada, contando 
apenas com um manual para consulta do passo a passo. Entretanto, esse manual foi feito de uma maneira nada acessível ao usuário, utilizando de uma linguagem não tão clara. Assim, mesmo com o manual, as dúvidas eram frequentes, de modo com que a necessidade de uso, mesma que pontual, do sistema ERP pelos colaboradores acarretava a necessidade de pedir auxílio ao financeiro, sobrecarregando os colaboradores deste setor. Entre janeiro a meados de março de 2020, o trabalho se desenvolvia de forma presencial, o que resultava em um relacionamento mais próximo entre os colaboradores do setor operacional com os colaboradores do setor financeiro. Contudo, com o avanço da COVID-19 e a transferência das atividades para a modalidade remota, essa proximidade física deixou de existir e com isso as interações para esclarecimentos em relação ao sistema ERP, que antes eram presenciais, agora necessitavam de um agendamento de reunião ou da comunicação por meio de aplicativos de mensagens, adicionando ainda mais tempo de espera ao pedido de compra ou reembolso.

- Espera: este desperdício ocorria no período pré-COVID-19, tanto na hora de inserir a solicitação de compras no sistema ERP (muitas vezes a compra era efetuada, mas a solicitação de compras só era inserida no sistema ERP poucos dias antes do vencimento do boleto da mesma, o que ocasionava em pedidos de prorrogação de vencimento do boleto para o fornecedor, ocasionando quedas não previstas no caixa da empresa), quanto entre as etapas entre inserir a solicitação e a aprovação do líder (para somente depois colaborador conseguir finalizar o processo). Em tempos de pandemia, este desperdício ocorre em uma escala bem menor, devido principalmente ao tempo que o líder da equipe demora para fazer a aprovação da solicitação para, dessa forma, o colaborador seguir com o processo de compra.

- Inventário: o desperdício ocorria na espera para recebimento da nota fiscal, e essa demora do fornecedor em encaminhar nota fiscal e boleto acarretava em o colaborador pedir para reemitir o boleto com vencimento em 30 dias. Quando a espera ultrapassava os 30 dias, era preciso solicitar uma reemissão da nota fiscal, o que gerava custos ao fornecedor.

- Defeitos: ocorria quando o colaborador inseria informações erradas ou esquecia alguma informação referente a solicitação de pedido de compras no sistema ERP. Quando o pedido, com informações incorretas, chegava no setor financeiro, era necessário recusar e devolver para que o colaborador o refizesse. Esta situação gerava um embaraço e descontentamento dos demais times em relação ao setor financeiro.

- Movimentação: no período pós-COVID-19 este desperdício se agravou, pois como o processo de compras não está mais tão recorrente no dia a dia dos colaboradores. Por estratégia da empresa de diminuir custos para se manter e sair com um caixa saudável desse período da pandemia, não foi redefinido ou acordado um novo procedimento para as solicitações de compras. Neste caso, ao abrir uma solicitação no sistema ERP, o colaborador precisa recorrer ao manual de compras e à política de compras da empresa. Nesse mesmo sentido da falta de inclusão na rotina, a empresa tem um alto nível de turnover, o que dificulta o treinamento de todos no que se refere ao sistema, gerando sempre dúvidas mesmo com os manuais e políticas disponíveis.

- Super processamento: este desperdício ocorre principalmente desde o início da pandemia causada pelo COVID-19, pois os colaboradores ainda não seguem um procedimento claro para a inserção das solicitações de compras no sistema ERP. Por este motivo é necessário que um colaborador do setor financeiro sempre confira os lançamentos da solicitação de compras no sistema ERP após o solicitante finaliza-lo. Isto evita ainda mais atrasos na finalização decorrente de um eventual erro de informações inseridas no sistema ERP.

- Habilidades das pessoas: este desperdício não foi identificado no processo de solicitação de compras propriamente dito, e sim na alta rotatividade de colaboradores. Deve-se mencionar que com a pandemia causada pelo COVID-19 acarretou na alta rotatividade de colaboradores, e devido à falta de uma gestão do conhecimento mais estruturada, há uma 
tendência na perpetuação dos erros cometidos na alimentação de informações no sistema ERP.

- Descontinuidade de fluxo: este desperdício foi identificado no fluxo de informações dentro do próprio sistema ERP, decorrente de um problema de interface, onde muitas vezes entre uma etapa e outra o colaborador precisa confirmar novamente a mesma informação já citada anteriormente. Por exemplo, no início da solicitação de compras o solicitante deve confirmar as informações inseridas; logo após o líder aprovar o pedido, o solicitante necessita acessar novamente a solicitação, confirmar as informações novamente, e só depois disto o processamento do pedido pode prosseguir.

\subsection{Preposição de melhorias e resultados preliminares}

As preposições de melhoria para cada desperdício identificado no processo de solicitação de compras são:

Superprodução: segundo as recomendações de Tapping et al. (2010), as ferramentas empregadas para eliminação/minimização deste desperdício a técnica de coleta de dados e o trabalho padronizado. A utilização destas ferramentas gerou a criação de um Manual de Compras, contendo:

- Glossário dos processos financeiros que sempre geravam muitas dúvidas nos colaboradores, descrevendo processos como despesas, despesas de custos variáveis, etc.;

- Glossário das informações que devem ser inseridas no sistema ERP que geravam duvidas nos colaboradores, descrevendo o significado de data de faturamento, etc.;

- Passo a passo detalhado, com um visual mais agradável e de fácil entendimento, do que o que descrito no antigo manual de compras, que possuía apenas um passo a passo generalista. As Figuras 3 e 4 apresentam a interface do Manual de Solicitação de Compras elaborado.

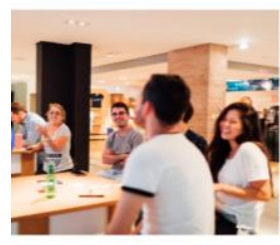

MANUAL
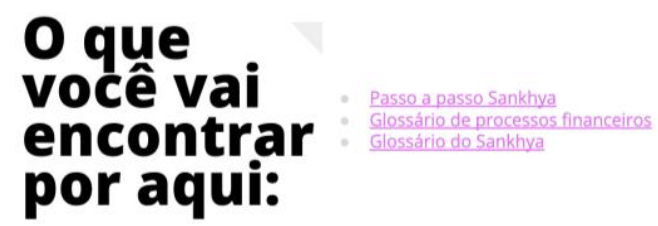
por aqui:

Figura 3 - Telas iniciais do Manual de Solicitação de Compras elaborado.

\section{Despesas}

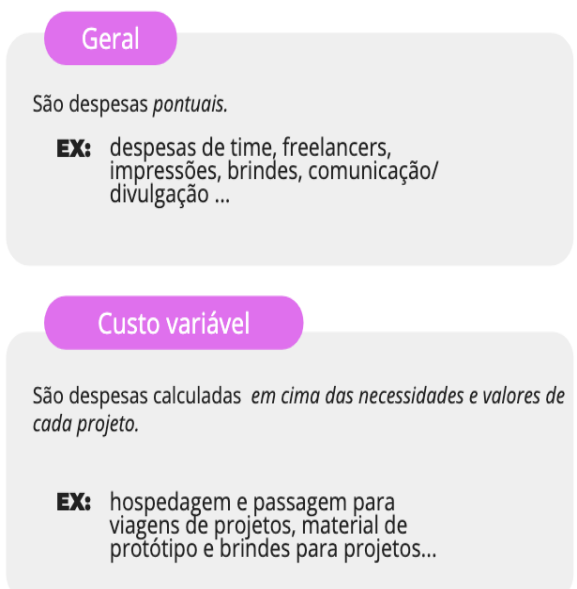

Glossário de processos financeiros > Despesas

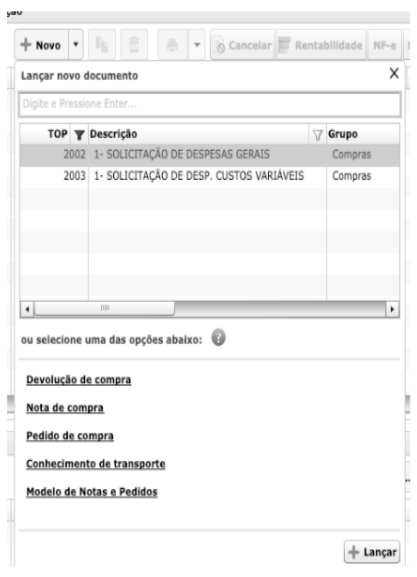

Figura 4 - Glossário do Manual de Solicitação de Compras elaborado. 
Aplicação destas medidas foram refletidas principalmente na diminuição de $30 \%$ das mensagens sobre dúvidas dos solicitantes para o setor financeiro (considerando um período de três meses antes e depois do início da pandemia e a coleta destas mensagens nos canais de comunicação disponibilizados para os colaboradores). Deste modo, a espera da resposta destas dúvidas foi eliminada e, consequentemente o lead time do processo de solicitação de compras foi reduzido.

Superprocessamento: com base na recomendação de Tapping et al. (2010) de utilizar as ferramentas de mapeamento do fluxo de valor, de trabalho padronizado, de elaboração de documentos, relatórios e comunicações enxutas, de controle visual, para eliminar este tipo de desperdício, foram utilizadas as metodologias blueprint e desing thinking. A blueprint trata de uma metodologia utilizada pela empresa para mapear os processos. Em termos gerais, ela é equivalente a um mapa de fluxo de valor, porém sem levar em consideração o tempo. Visou-se, com a blueprint, identificar como o processo realmente acontece na tentativa de entender os maiores pontos de fricção entre usuário solicitante e o sistema ERP. A partir do entendimento do processo real de solicitação de compras, e, considerando o processo ideal de solicitação de compras, foi efetuada uma entrevista de empatia com três usuários solicitantes do sistema ERP. Esta entrevista teve como base a metodologia design thinking, que utilizada pela empresa para entender e resolver um problema tendo em vista uma dor real do usuário e não aquela que se acredita ser uma dor do usuário. Como resultados desta entrevista de empatia identificou-se que havia uma insegurança do usuário em relação aos dados que ele mesmo inseria no sistema ERP no momento da solicitação de compra, e que eventuais erros por ele cometido fosse lhe comunicado o mais breve possível para não atrasar ainda mais o processo. Atualmente, um colaborador do financeiro é responsável para conferir diariamente todos os lançamentos inseridos no sistema ERP. Identificado algum erro no sistema, o solicitante é comunicado no mesmo dia útil para corrigi-lo.

A aplicação destas ferramentas possibilitou identificar as principais dores do usuário, que resultou no adiantamento do processo de conferência da solicitação de compras pelo setor financeiro. Anteriormente esta conferência no pedido de solicitação de compras era efetuada na semana do pagamento, ou seja, cerca de 20 dias depois da inserção do pedido no sistema ERP. Atualmente esta conferência é feita todos os dias no sistema ERP. Houve um impacto significativo na eliminação do tempo de espera do solicitante. Houve um ganho de confiança em relação ao usuário, pois o tempo de resposta do setor financeiro sobre um eventual erro na solicitação de compras é quase que imediatamente comunicação ao solicitante. Uma sugestão é adquirir um pacote no sistema ERP que informatize o contato do setor financeiro diretamente com os bancos envolvidos, eliminando a necessidade da inserção de dados solicitações de compra em banco.

Espera: para minimizar esse desperdício, e seguindo as recomendações de Tapping et al. (2010) - para eliminação deste desperdício empregar técnicas de coleta de dados, relatórios e comunicados enxutos, balanceamento de carga de trabalho, etc. - foram efetuadas a entrevista de empatia, comunicação semanal e emprego de mensagem de comunicação sobre o processo de solicitação de comprar para o líder.

A partir da entrevista de empatia foi identificado como uma dor do usuário à espera do líder em aprovar uma solicitação de compra, e também o fato do solicitante não ser comunicado sobre a aprovação da sua solicitação. Primeiramente, foi adotada uma comunicação semanal com os líderes para alertar sobre processos a serem aprovados. Esta medida não gerou redução da espera. Diante disto, padronizou-se que o solicitante, no momento da solicitação, enviasse uma mensagem para o seu líder analisar o pedido. Em virtude da aderência dos líderes, esta iniciativa, aos poucos, reduziu o tempo de espera. Além disto, foi padronizado que nas reuniões mensais com os colaboradores é destacado, por meio de um slide, para o colaborador conferir se seus pedidos foram aprovados pelo líder e colaborador finalizar o processo. A Figura 5 apresenta exemplos de slides levados as reuniões gerais mensais. 


\section{Lançamentos
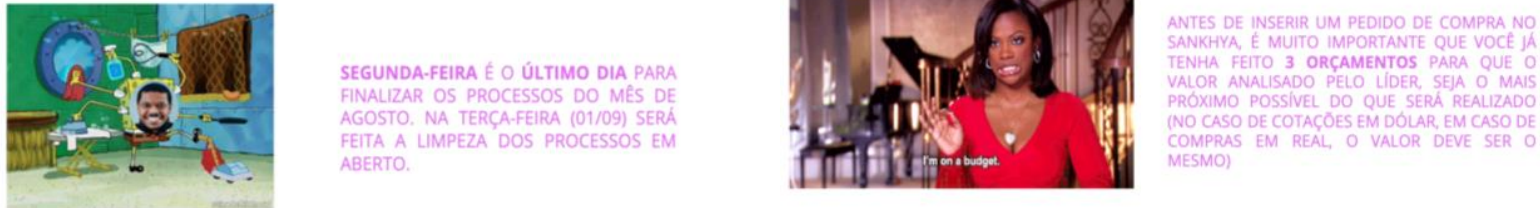

Figura 5 - Exemplo dos slides levados as reuniões gerais mensais do setor financeiro.

Por depender de uma aprovação do líder, esta etapa ainda gera um desperdício considerável para do processo de solicitação de compras. Sugere-se alterar funções no sistema ERP do tipo "acompanhe seu pedido", com mensagens de notificação da conclusão de cada etapa do processo. Outra sugestão é lotar com colaborador do setor financeiro somente para o processo de compras. Este colaborador seria responsável por realizar todas as compras, acompanhamento do orçamento de cada time, receber as demandas de compras. Tal sugestão poderia acarretaria na eliminação de dados incorretos no sistema ERP e consequentemente facilitaria o fechamento mensal em termos de relatórios de contabilidade da empresa.

Como principal efeito das ações para minimizar o desperdício de espera tem-se a diminuição do tempo entre as etapas de 'aprovação do líder' e a finalização do processo pelo solicitante, passando de em torno de 2.400 min para 960 min. Em uma eventual contratação de um colaborador dedicado ao processo de compras, estima-se que o processo diminuiria em várias etapas: de 480 min de espera entre solicitar e o líder aprovar, para 0 min (caso essa mesma pessoa também fique responsável pelo controle do orçamento, junto aos líderes); de 2.400 min entre o líder aprovar e contactar o fornecedor para 0 min (visto que a própria pessoa iria fazer todo o processo. Essa etapa de aprovação do líder poderia ser excluída. E essa pessoa ter reuniões semanais de $30 \mathrm{~min}$ com cada líder para poder alinhar as compras da semana); entre receber a nota fiscal e o boleto e faturar, passaria de $480 \mathrm{~min}$ para no máximo $90 \mathrm{~min}$. Além disso, depois que essa pessoa fosse treinada, também diminuiria o tempo que ela levaria para realizar o processo, não apenas o tempo de espera: estima-se que o tempo para solicitar uma compra passaria de $20 \mathrm{~min}$ pra $10 \mathrm{~min}$, e o tempo para faturar passaria de $15 \mathrm{~min}$ para $5 \mathrm{~min}$.

Inventário: para a eliminação deste desperdício, segundo a recomendação de Tapping et al. (2010), foi empregado a técnica de controle visual. A política de compras da empresa foi reescrita e disponibilizada em um formato de fácil entendimento utilizando a metodologia do Visual Law ${ }^{\circledR}$. Esta metodologia se trata de uma subárea do Legal Design ${ }^{\circledR}$, que emprega elementos visuais em informações jurídicas para torná-las mais claras e compreensíveis, buscando tornar as informações jurídicas em algo que qualquer pessoa seja capaz de entender.

$\mathrm{O}$ setor financeiro passou a barrar os processos que estivessem com notas fiscais e boletos fora da data de competência ou com prazo menor que 30 dias para pagamento (regra da empresa). Com isso, os colaboradores devem estar mais atentos com essas informações. Alguns poucos casos não foram possíveis de serem atendidos na forma de pagamento dentro dos 30 dias. Nestas situações é efetuada uma análise de caixa e da necessidade real da compra com o fornecedor indicado; se o caixa estiver saudável e realmente for imprescindível a compra com aquele fornecedor, a compra é autorizada. A Figura 6 apresenta a interface da política de compras utilizado o Visual Law ${ }^{\circledR}$. 


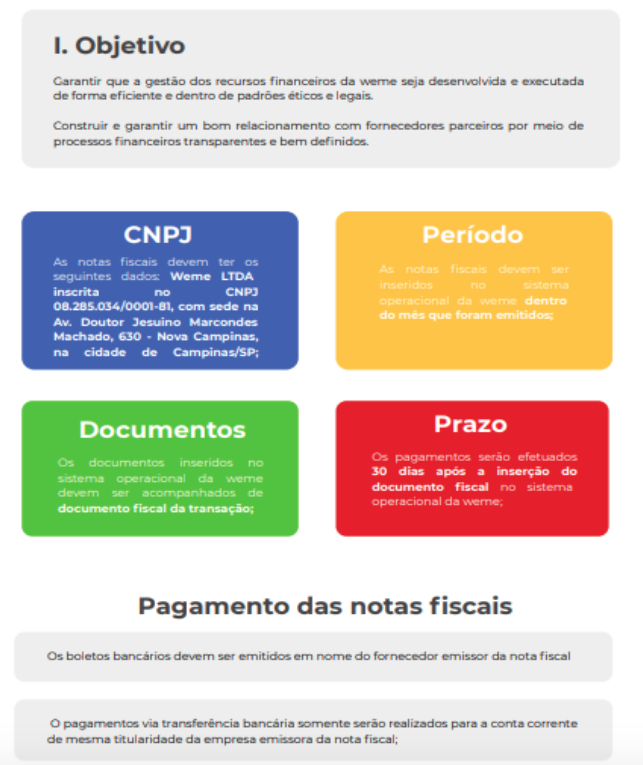

Figura 6 - Estrutura da política de compras utilizando o Visual Law ${ }^{\circledR}$.

Defeitos: além da criação do manual de solicitação de compras, ajuda de um colaborador do setor financeiro para acompanhar o solicitante que peça auxílio ajuda para o preenchimento da solicitação no sistema ERP foram adotadas as seguintes ações: criação de um de um canal de comunicação de Slack ${ }^{\circledR}$ e melhora na comunicação das informações do setor financeiro nas reuniões gerais mensais.

O canal de comunicação criado no Slack ${ }^{\circledR}$ - ferramenta utilizada na época para comunicação interna da empresa - servia para que, antes de solicitar ajuda de um membro do setor financeiro, o solicitante visualizasse neste canal de sua mesma dúvida já havia sido esclarecida. Este canal de comunicação não trouxe resultados positivos por dois principais motivos: os colaboradores ao invés de mandar a dúvida nesse canal, sempre acabava mandando mensagens por outro canal de comunicação para algum membro do financeiro; a conta utilizada pela empresa no Slack ${ }^{\circledR}$ era gratuita, logo algumas funcionalidades da ferramenta não estavam disponíveis nessa versão. Um dos prejuízos era a impossibilidade de salvar o histórico de conversas no Slack para usuários com conta gratuita. Deste modo, esse canal de comunicação foi extinto.

Outra medida adotada na tentativa de eliminar esse desperdício foi uma comunicação mais leve, divertida e clara durante a reunião Geral, sempre levando dúvidas que surgiram ao longo da semana para explicar para todos, caso seja a dúvida de outra pessoa também. Além destas ações, é importante destacar, como sugestão, que a contratação de um colaborador para o setor financeiro, focado apenas na parte de compras, também traria benefícios da garantia de informações mais corretas e ganho de tempo, uma vez que os demais membros do financeiro não precisariam para outras atividades para dar esse suporte a cada usuário.

O manual de solicitação de compras, bem como os avisos sobre prazo de finalização das solicitações, diminuiu a demanda por ajuda do setor financeiro. Maiores reduções no desperdício de defeitos no processo seriam atingidas com a contratação de um colaborador voltado para os processos de compras, pois seriam eliminadas as esperas entre as etapa de o 'líder aprovar' e o 'colaborador finalizar o processo', passando de $2.400 \mathrm{~min}$ para $960 \mathrm{~min}$. No caso de um colaborador dedicado ao processo de compras, estima-se que os tempos de espera entre a abertura da solicitação e aprovação do líder passaria de $480 \mathrm{~min}$ para $0 \mathrm{~min}$; entre o líder aprovar e contactar o fornecedor de 2.400 min para 0 min. Este teria reuniões semanais de $30 \mathrm{~min}$ com cada líder para alinhar as compras semanais.

Movimentação: para eliminar este tipo de desperdício foi a elaborado o manual de solicitação de compras, agregando todas as informações mais úteis e procuradas, como o link para acesso no Sankhya $^{\circledR}$, para que o solicitante não tenha que procurar as informações que deseja em diferentes 
documentos. Os links para acesso desse manual e da política de compras se encontram facilmente em um canal chamado "links úteis" no Discord ${ }^{\circledR}$ (novo canal de comunicação interna da empresa), sem que a pessoa tenha que procurar em vários lugares. Estima-se que, com essa concentração dos links úteis em um único documento, cada vez que o colaborador precisa fazer uma solicitação ele tenha eliminado cerca de 5 min pra procurar todos os links.

Descontinuidade de fluxo: para minimizar esse tipo de desperdício os colaboradores do setor financeiro revisaram alguns itens de menor complexidade dentro do sistema ERP, como por exemplo deixar campos com informações mais relevantes, eliminar algumas informações que não agregam valor e que apenas geram confusão, revisão de todos os produtos cadastrados, limpeza de dados obsoletos, mudança de nomenclatura de campos no sistema ERP, etc. Padronizou-se que no primeiro dia útil de cada mês deverá ser efetuada a limpeza da base de dados, onde são excluídos processos que foram abertos no mês anterior e não foram finalizados até o fechamento do mês. Com esta padronização de exclusão de solicitações não finalizadas dos meses anteriores a descontinuidade de fluxo passou de tempos de espera de cerca de uma semana para somente 1 dia e as solicitações paradas no sistema ERP diminuíram cerca de $20 \%$ em relação a cada 100 processos realizados.

Deve-se salientar que somente essas ações não são suficientes para eliminar completamente esse desperdício. Para a realização de todas as melhorias apontadas pelos usuários do sistema ERP e deixá-lo com mais funcionalidades é necessário dispor de um valor adicional de $60 \%$ na mensalidade do sistema e um valor de aproximadamente $30 \%$ do custo inicial para inclusão dos pacotes de contabilidade, pessoal e dashboard no sistema ERP, o que no atual contexto da empresa essa implementação é inviável.

\subsection{Mapa do Estado Futuro}

O mapa do VSM futuro foi construído levando-se em consideração os resultados preliminares e as sugestões de melhoria propostas para o processo de solicitação de compras e solicitação de reembolso. Com a elaboração do mapa do estado futuro buscou-se estimar os eventuais ganhos nos processos de solicitação de compras e reembolso. Considerando os resultados preliminares e as sugestões de ações para eliminação dos desperdícios identificados, a Figura 7 apresenta o mapa do estado futuro do processo de solicitação de compras.

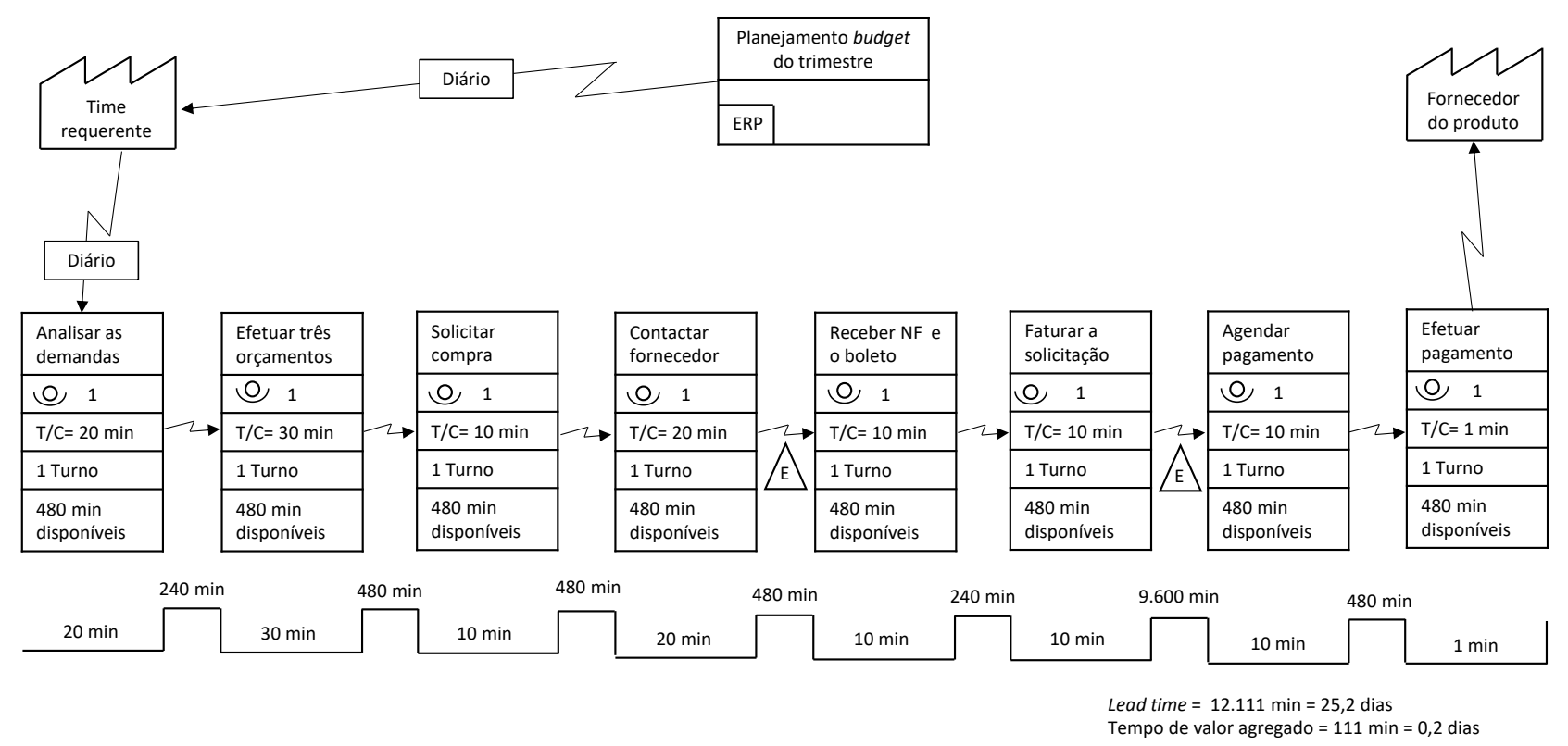

Figura 7 - Mapa do estado futuro do processo de solicitação de compras pós-COVID-19. 
Executando-se as sugestões de melhoria, considerando o mapa do estado futuro, estimam-se as seguintes reduções:

- Redução do lead time de solicitação de compras pré-COVID-19 em 26\%;

- Redução do tempo de valor agregado do processo de solicitação de compras pré-COVID-19 de $84 \%$;

- Redução do lead time de solicitação de compras pós-COVID-19 de 22\%;

- Redução do tempo de valor agregado do processo de solicitação de compras pré-COVID-19 $50 \%$.

Deve-se mencionar que a contratação de um colaborador dedicado para o processo de compras - podendo ser nível júnior - implicaria na redução efetiva destes leads times. Isto por que este colaborador seria devidamente treinado, reduzindo os tempos de ciclo de cada etapa e haveria uma redução ganho na espera das etapas, pois este colaborador faria o controle de budget junto ao líder de cada squad, já analisando a viabilidade da compra. Outra ponderação é que no período de pandemia não se faz necessário esta contratação, pois a empresa está trabalhando com corte de gastos e são poucas as compras que estão ocorrendo. Porém, vislumbrando o retorno de trabalho presencial, essa demanda aumentaria bastante o que ratifica essa nova contratação.

\section{Conclusões}

O presente trabalho aplicou ferramentas do lean office nos processos de solicitação de compras no setor financeiro de uma empresa com Centro de Serviços Compartilhados (CSC). Foram elaborados mapas do fluxo de valor (VSM) do estado atual e do estado futuro. Com isto conclui-se que:

- As propostas de melhoria sugeridas indicam uma redução do lead time de solicitação de compras em $26 \%$ em relação ao período pré-COVID-19 e de $22 \%$ considerando-se o período pós-COVID-19. Com a contratação do novo colaborador, o processo se tornaria enxuto, pois este colaborador irá eliminar algumas etapas do processo;

- O mapeamento do fluxo de valor dos processos de compras permitiu identificar os desperdícios que anteriormente eram difíceis de serem detectados pelo setor financeiro da empresa. Foram identificados 9 desperdícios do lean office no processo de compra.

- O lean office pode contribuir significativamente para melhora dos processos e atividades de uma organização, principalmente em funções administrativas de suporte.

\section{Referências}

Benini, L. \& Batista, F. R. R. (2019). Aplicação da filosofia lean service para a otimização do processo de serviço de uma empresa júnior de consultoria. The Journal of Engineering and Exact Sciences, 5(4) 0325-0337. doi https://doi.org/10.18540/jcecvl5iss4pp0325-0337

Bulhões, I. R. (2009) Diretrizes para implementação de fluxo contínuo na construção civil: uma abordagem baseada na Mentalidade Enxuta. Tese de Doutorado, Universidade Estadual de Campinas, Campinas, SP.

Calsavara, N. A. (2016). Aplicação do pensamento Lean Office e mapeamento do fluxo de valor no processo de concepção de unidades bancárias de uma empresa do setor financeiro. GEPROS Gestão da Produção, Operações e Sistemas, 11(3), 105-117.

Cardoso, G. O. A. \& Alves, J. M. Análise crítica da implementação do Lean Office: um estudo de casos múltiplos. GEPROS Gestão da Produção, Operações e Sistemas, 8(1), 23-35.

Cardoso, G. O. A., Souza J. P. E. \& Alves J. M. (2012). Lean office aplicado em um processo de auditoria de certificação de sistema de gestão da qualidade aeroespacial. XXXII Encontro nacional de Engenharia de Produção, Bento Gonçalves, Brasil.

Chen, J. C. \& Cox, R. A. (2012). Value Stream Management for Lean Office - A Case Study. American Journal of Industrial and Business Management, 2, 17-29. 
Costa R.S. \& Jardim E. G. M. (2010). Os cinco passos do pensamento enxuto. Rio de Janeiro. Disponível em: http://www.trilhaprojetos.com.br, Acesso em jul. 2020.

Evangelista, C. S., Grossi, F. N. \& Bagno R. B. (2013). Lean Office - escritório enxuto: estudo da aplicabilidade do conceito em uma empresa de transportes. Revista Eletrônica Produção \& Engenharia, 5(1), 462-471.

Ferreira, T. M. M. M. (2016). Aplicabilidade do lean no setor bancário - estudo de caso. Dissertação de Mestrado. Instituto Politécnico de Lisboa, Instituto Superior de Contabilidade de Administração de Lisboa, Lisboa, Portugal.

França, S. V. S. (2013). Implementação de Ferramentas de Lean Manufacturing e Lean Office: Indústria metálica, plástica e gabinete de contabilidade. Dissertação de Mestrado, Faculdade de Engenharia da Universidade do Porto, Porto, Portugal.

Freitag, A. E. B., Santos, J. C. \& Reis, A. C. (2018). Lean office and digital transformation: a case study in a services company. Brazilian Journal of Operations \& Production Management, 15, 588-594.

Freitas, R. C., Freitas, M. C. D. F. \& Menezes, G. G.; Odorczyk, R. S. (2018). Lean Office contributions for organizational learning. Journal of Organizational Change Management. https://doi.org/10.1108/JOCM-06-2017-0221

Gentil, J. V. \& Terra, L. A. A. (2015). As vantagens competitivas do lean office. $11^{\circ}$ Congresso Brasileiro de Sistemas: o pensamento sistêmico e a interdisciplinaridade Franca, Brasil.

Gil, A. C. (2002). Como elaborar projetos de pesquisa. 4 ed. Atlas.

Greef, A. C., Freitas, M. C. D. \& Romanel, F. B. (2012). Lean Office: Operação, Gerenciamento e Tecnologias. Atlas.

Herzog, A. L. (2003). O escritório enxuto. Revista Exame, 789, 60-66.

Ho, S. K. \& Cicmil, S. (1996). Japanese 5-S practice. The TQM Magazine, 8(1), 45-53.

Imai, M. (2010). Kaizen Institute. 2010. Disponível em: <http://br.kaizen.com/artigos-elivros/artigos/kaizenbaixando-os-custos-e-melhorando-a-qualidade.html>. Acesso em: out 2019.

Ishizaka, A Y., Dinis, L.S., Watanabe, N. L., Sales, S. R. \& Sagawa, J. K. (2016). Lean Office: Uma aplicação no Departamento de Marketing de uma instituição financeira. Produto \& Produção, 17(4), 41-61.

Lareau, W. (2002). Office Kaizen: Transforming office operations into a strategic competitive advantage. United States of America: ASQ Quality Press.

Locher, D. (2011). Lean Office and Service Simplified - The definitive how-to guide. Boca Raton.

Magalhães, J. C., Alves A. C., Costa, A. \& Rodrigues, A. R. N. (2019). Improving processes in a postgraduate office of a university through lean office tools. International Journal for Quality Research, 13(4), 797-810.

McManus, H. (2003). Product development value stream analysis and mapping manual (PDVMS) - Alpha Draft. Cambridge: MIT.

Mendonça, F. C. \& Rotta I. S. (2018) Filosofia lean em serviços - uma revisão bibliográfica, VIII Congresso Brasileiro de Engenharia de Produção, Ponta Grossa, PR, Brasil.

Monteiro, J., Alves, A. C., \& Carvalho, M. do S. (2017). Processes improvement applying Lean Office tools in a logistic department of a car multimedia components company. Procedia Manufacturing, 13, 995-1002. ttp://doi.org/10.1016/j.promfg.2017.09.097.

Monteiro, M. F. J. R., Pacheco, C. C. L., Dinis-Carvalho, J. \& Paiva, F. C. (2015) Implementing Lean Office: A Successful Case in Public Sector. FME Transactions, 43(4), 303-310.

Ohno, T. (1997). O Sistema Toyota de Produção: além da produção em larga escala. Bookman. Oliveira, J. D. (2003). Escritório Enxuto (Lean Office). Lean Institute Brasil. Disponível em: <http://www.lean.org.br/artigos/57/escritorio-enxuto-(lean-office).aspx>. Acesso em: jul. 2020.

Picchi, F.A. (2002). Lean na administração. Lean Summit, Gramado, Brasil. 
Ribeiro, D. R. S., Bonfante, M. C., Frazzon, E. M. \& Forcellini, F. A. Mapeamento do fluxo de valor e uso da simulação integrada lean com sistemas ciber-físicos em uma indústria de embalagens flexíveis. Revista Produção Online, 19(1), 346-374.

Roos, C., Sartori, S. \& Paladini, P. E. (2011). Uma abordagem do Lean Office para reduzir e eliminar desperdícios no fluxo de valor de informações e conhecimentos. Encontro Nacional de Engenharia de Produção, Belo Horizonte, Brasil.

Ross, C. \& Follmann, N. (2009). Lean Office para um problema de implementação de bolsas em um programa de pós-graduação em Engenharia de Produção. Simpósio de Engenharia de Produção, Bauru, Brasil. $\quad$ Disponível em:<http://www.simpep.feb.unesp.br/anais_simpep.php?e=4>. Acesso em: jul. 2020.

Rother, M. \& Shook, J. (2003). Aprendendo a enxergar. Lean Institute Brasil.

Santos, R. V. S. (2010). Evidências de lean accounting em empresas enxutas: um estudo de caso exploratório. XVII Congresso Brasileiro de Custos, Belo Horizonte, Brasil.

Scheibler, B. A., Luz, M. C. L., Santos, J. S., Bochi, C. G. \& Jacintho J. R. M. (2014). Aumento da eficiência através da implantação de Centro de Serviços Compartilhados: estudo de caso em uma instituição financeira. IV Congresso de Sistemas Lean, Porto Alegre, Brasil.

Seraphim, E. C., Silva, I. B. \& Agostinho, O. L. (2010). Lean Office em organizações militares de saúde: estudo de caso do Posto Médico da Guarnição Militar de Campinas. Gestão \& Produção, 17(2), 389-405.

Sukma, H. N., Amrina, E. \& Hasan, A. (2018). Evaluasi Proses Pelayanan Administrasi Kependudukan dengan Metode lean office. Journal Optimasi System Industry, 17(2), 171187.

Tammela, I., Cardoso, R. \& Almeida, C. C. (2017). Lean service e lean office: uma revisão bibliográfica comparativa. XXXVII Encontro Nacional de Engenharia de Produção. Joinville, SC, Brasil.

Tapping, D., Dunn. A., Fertuck. D. \& Baban. V. (2010). Lean Office Demystified II: using the Power of the Toyota Production System in your Administrative, Desktop and Networking Environments. Chelsea: MCS Media.

Tapping, D. \& Shuker, T. (2003). Value Stream Management for the Lean Office: 8 steps to planning, mapping, and sustaining lean improvements in administrative areas. 1. ed. Boca Raton: CRC Press.

Tice, J., Ahouse, L. \& Larson, T. (2005). Lean Production and EMS: aligning environmental management with business priorities. Environmental Quality Management, 5(2), 1-12.

Turati, C. R. \& Musetti, A. M. (2006). Aplicação dos conceitos Lean Office no setor administrativo público. XXVI Encontro Nacional de Engenharia de Produção, Fortaleza, Brasil.

Turati, R. C. (2007). Aplicação do Lean Office no Setor Administrativo Público. Dissertação de mestrado, Universidade de São Paulo, São Carlos, SP, 2007.

Turrioni, J. B. \& Mello, C. H. P. (2009). Metodologia de Pesquisa em Engenharia de Produção e Gestão de Operações. Campus.

Umeda, M. (1997). As sete chaves para o sucesso do 5S. Belo Horizonte: Fundação Christiano Ottoni, Escola de Engenharia da UFMG.

Womack, J. P., \& Jones, D. T. (1996). Lean Thinking: Banish Waste and Create Wealth in your Corporation. (F. Press, Ed.). Free Press.

Womack, J. P., Jones, D. T. \& Roos, D. (1990). The Machine That Changed the World: The Story of Lean Production. Rawson Associates.

Womack, J. P. \& Jones, D. T. (2004). A mentalidade enxuta nas empresas: Elimine o desperdício e crie riqueza. Elsevier.

Womack, J. P.; Jones, D. T. \& Roos, D. (1992) A máquina que mudou o mundo. 14. ed. Campus. 